\title{
Ciência, liberdade e criação no pensamento de Pedro Américo*
}

\section{Science, freedom and creation in the thought of Pedro Américo}

\author{
Vinícius Carvalho da Silva \\ https://orcid.org/0000-0002-1061-2727 - E-mail: vinicius_c_silva@ufms.br
}

\begin{abstract}
RESUMO
Neste trabalho buscamos apresentar a concepção de ciência de Pedro Américo, discorrendo sobre sua contraposição ao positivismo, a defesa do "racionalismo experimental", e a importância da liberdade, da autonomia e da busca da verdade como os valores centrais da Filosofia Natural. Por último, veremos como Arte e Ciência formam, no pensamento de Pedro Américo, a base de um ideal de vida e cultura, pautado pela liberdade de criação.
\end{abstract}

Palavras-chave: Filosofia Natural. Liberdade. Verdade. Racionalismo.

\begin{abstract}
In this work, we seek to present Pedro Américo's concept of science, discussing his opposition to positivism, a defense of "experimental rationalism", and an importance of freedom, capacity and the search for truth as the values of Natural Philosophy. Finally, we will see how Art and Science form, in the thought of Pedro Américo, a basis for an ideal of life and culture, guided by the freedom of creation.
\end{abstract}

Keywords: Natural Philosophy. Freedom. Truth. Rationalism.

\footnotetext{
* Agradeço a Antônio Augusto Passos Videira, da Universidade do Estado do Rio de Janeiro, por ter me apresentado ao Pedro Américo filósofo, que eu tanto já admirava como pintor, e por ter lido o manuscrito e oferecido seus apontamentos. À Biblioteca Nacional, no Rio de Janeiro, onde consultei A ciência e seus sistemas e outras fontes, e à Biblioteca do Museu Imperial, onde puder ler as Considerações filosóficas sobre as Belas Artes e jornais de época sobre Pedro Américo. Fui recebido na Biblioteca do Museu Imperial por sua responsável, a historiadora Claudia Costa, que, junto de sua equipe, permitiu-me agradáveis tardes de estudo. Agradeço também ao incentivo que me foi dado para a redação desse trabalho por Judikael Castelo Branco, da Universidade Federal do Tocantins, e pelos colegas do grupo Physikos - Estudos de História e Filosofia da Física e da Cosmologia da Universidade Federal do Mato Grosso do Sul.
} 


\section{Introdução}

No presente artigo analisaremos a concepção de ciência de Pedro Américo, sua crítica ao materialismo, empirismo, e ao positivismo e sua defesa do "racionalismo experimental", destacando a importância da liberdade, da autonomia e da busca da verdade como valores supremos da investigação natural. Para tanto, primeiro seremos rapidamente apresentados ao autor, em seguida nos deteremos brevemente sobre o contexto intelectual de sua época, e então passaremos ao seu trabalho. Veremos sua defesa do veritismo, sua adesão à atitude filosófica de Copérnico e Galileu, e por fim, veremos como Arte e Ciência constituem, no pensamento de Pedro Américo, expressões da liberdade de criação humana, formando as bases de um ideal de vida.

Em dado momento será útil nos determos em alguns tópicos, como o Renascimento, a importância da Filosofia Natural, o pensamento e a obra de Galileu. E por que em alguns momentos pareceremos demasiado imersos em tais temáticas? Porque constituem pontos fulcrais da filosofia de Pedro Américo. Discutir, por exemplo, o veritismo de Galileu, é fundamental para compreendermos como Galileu representa no pensamento de Pedro Américo, o modelo do filósofo natural. Nosso tom poderá parecer elogioso ao trabalho do autor estudado, tomando posição por sua epistemologia. Que seja. Não acreditamos em neutralidade filosófica e nem postulamos uma posição descritivista. Não somente apresentamos o pensamento de Pedro Américo como acreditamos que sua defesa do veritismo, da Filosofia Natural e da liberdade da ciência foram, e de certo modo permanecem, fundamentais, a despeito de todas as diferenças históricas entre o seu tempo e o nosso.

Se nos cabe alguma crítica mais contundente ao pensamento de nosso autor, ela se dirige ao seu veritismo. Em linhas gerais, acreditamos em um veritismo axiológico, isto é, que a "busca da verdade" deve ser um valor para as ciências, mas pensamos que todo veritismo, inclusive o axiológico, deve ser objeto de rigorosa crítica, para que escape a uma visão de certo modo ingênua acerca da "verdade" e para que não endosse uma visão colonial, hegemônica, de verdade. A verdade como instrumento de poder alcança níveis totalitários evidentemente indesejáveis. Um veritismo crítico axiológico é aquele que abarca uma teoria da verdade como elemento fundamental de uma filosofia da ciência sem deixar de problematizar o conceito de verdade e de considerar as limitações que a ciência possui. Acreditamos que Pedro Américo não era um veritista ingênuo, mas poderia ter sido mais crítico e explícito quanto ao que entende por verdade nas ciências naturais. Feita essa brevíssima crítica à filosofia do autor, passemos à sua vida.

\section{Breves notas biográficas}

Pedro Américo de Figueiredo e Melo nasceu em Areia, na Paraíba, em 1843, e faleceu em Florença, na Itália, aos 62 anos, em 1905, o mesmo ano em que Albert Einstein publicou uma série de cinco artigos na Annalem der Physik contribuindo para o assentamento das bases de uma nova física em dois de seus pilares; a relatividade e a teoria quântica. Pedro Américo, filósofo da ciência, não viveu para presenciar as profundas transformações intelectuais que se seguiriam naquele primeiro quarto de século e que moldariam uma nova concepção física do mundo.

Em geral, o brasileiro que conhece Pedro Américo o conhece como pintor, um dos nossos maiores pintores acadêmicos ao lado de nomes como Victor Meirelles e Manoel de 
Araújo Porto Alegre. Obras icônicas de Pedro Américo fazem parte de nosso imaginário popular, como aquela em que pinta com heroísmo mítico o grito do Ipiranga, dado, na realidade, em condições bem mais modestas, conforme a historiografia contemporânea. Suas batalhas de grandes proporções são igualmente famosas e reconhecidas como exemplares das mais elevadas realizações artísticas brasileiras, destacando-se a "Batalha de Campo Grande" (1871), no Museu Imperial de Petrópolis, e a "Batalha do Avay" (1877), obra de imensas proporções, exposta no Museu Nacional de Belas Artes, no Rio de Janeiro. Ambas, feitas sob o mecenato da Coroa Imperial, retratam momentos terríveis da Guerra do Paraguai. A vida e obra de Pedro Américo não passam em branco no mundo cultural brasileiro, tendo sido objeto de algumas biografias e teses de doutoramento (BARROS, 2006). ${ }^{1}$

O Pedro Américo filósofo da ciência, contudo, é praticamente desconhecido, inclusive pela filosofia brasileira. O seu interesse pelas ciências naturais data de sua infância. Aos dez anos participou como desenhista, da "Missão Exploradora" do naturalista francês Louis Jacques Brunet, que por vinte meses percorreu a Paraíba, parte de Pernambuco, Ceará, Rio Grande do Norte e Piauí (OLIVEIRA, 1943). Podemos pensar o quanto tal experiência o marcou, incutindo- Ihe sentimentos científicos e filosóficos, um profundo gosto pela investigação da natureza, a observação da fauna, da flora, da gente, e dos céus do Brasil.

Estudou Belas Artes no Rio de Janeiro e ciências sociais na Sorbonne, na França, onde se aproximou das ciências naturais e experimentais. Conforme Oliveira (1943), teve como "mestres" científicos o fisiologista Claude Bernard (1813-1878), um dos pioneiros da chamada medicina experimental, o químico e físico César-Mansuète Despretz (1791-1863) e o químico Henri Sainte-Claire Deville (1818-1881). Em 1868 defendeu a tese A Ciência e seus Sistemas: Questões de História e Filosofia Natural na Universidade de Bruxelas, recebendo o título de doutor em ciências naturais. Inicialmente a tese de Pedro Américo teria outro título, que refletia sua grande preocupação, De la Liberté, de la Méthode et de l'Espirit de systeme dans l'étude de la Nature, [Da Liberdade, do Método e do Espírito do sistema no estudo da Natureza]. O que caracteriza a Filosofia Natural, para Pedro Américo, não é somente um método, mas uma atitude, um "espírito", marcado pela inspiração, inventividade e criatividade artísticas, bem como pelo pleno exercício da liberdade espiritual.

O clima intelectual da Europa, nos parece, era compreendido como fundamental por Pedro Américo. No Velho Continente ele estava em contato com movimentos de vanguarda, com a efervescência intelectual dos grandes centros, frequentava cursos, palestras e conferências, como as de Faraday no Colégio de França. Em 1862, ele se inscreveu na Faculdade de Ciências de Paris, onde teria agitada vida acadêmica. Silvano Alves Bezerra da Silva, no estudo introdutório às "Considerações filosóficas sobre as Belas Artes entre os antigos" (2006), lembra que em carta a Pedro II, de 6 de janeiro de 1862, Pedro Américo pede ao monarca o financiamento para permanecer mais dois anos em Paris (SILVA apud MELO, 2006).

A permanência na Europa o permitia um desejável distanciamento do debate político e intelectual do Brasil, criando uma região segura e confortável para sua batalha contra o positivismo por aqui crescente. Sua inserção na rede de mecenato de Pedro II se prolongaria, e, em

\footnotetext{
${ }^{1}$ Francisca Argentina Gois Barros defendeu Tese de Doutoramento em Educação pela Faculdade de Educação da Universidade Federal do Ceará, intitulada A arte como princípio educativo: Uma nova leitura biográfica de Pedro Américo de Figueiredo e Melo. Barros lista seis biógrafos de Pedro Américo, enumerando as biografias escritas até 2006: (1) Luís Guimarães Jr. (1871), (2) Cardoso Oliveira (1943), (3) Horácio Almeida (1943), (4) Donato Mello Jr. (1983), (5) Luís Martins (1994) e (6) Madalena Pekala (1995). Não é nosso interesse, aqui, nos deter em tais minúcias, e saber, ao todo, quantos trabalhos sobre Pedro Américo foram produzidos. $O$ quadro apresentado por Barros até 2006 nos é suficiente para verificarmos que Pedro Américo despertou interesse da historiografia brasileira, embora não possamos afirmar que esteja dentre nossos personagens mais celebrados.
} 
sua volta ao Brasil, sua aproximação com a Coroa Ihe renderia boas posições institucionais, como uma cadeira de professor na Academia de Bellas Artes ${ }^{2}$.

Pedro Américo esteve próximo à Coroa antes, durante e após viver na Europa, e seu pensamento filosófico, como veremos, endossava uma visão de ciência que, senão era propriamente à do Imperador, ao menos combatia inimigos comuns, os positivistas. É bastante natural que, em nome de suas filiações políticas - e não somente de sua epistemologia - fosse bem recebido por monarquistas e mal recebido pelos republicanos positivistas. No entanto, o fato que parece claro é que a recepção do trabalho filosófico de Pedro Américo é praticamente inexistente.

As poucas biografias, os artigos, os estudos sobre Pedro Américo se devem, sobretudo, ao pintor. Barros destaca que a tese de Pedro Américo demorou mais de cem anos para ganhar uma tradução em língua portuguesa. Em seu tempo o seu trabalho filosófico ficou praticamente desconhecido do público. A recepção acanhada rendeu um estudo praticamente isolado de Silvio Romero, que "em um importante estudo que fez sobre Filosofia no Brasil, em 1878, inclui Pedro Américo no rol dos filósofos brasileiros" (BARROS, 2006, p. 139). No entanto, Barros enfatiza que a análise que Romero faz de Pedro Américo - análise duramente crítica e negativa - incorre no erro daqueles que criticam o que não conhecem, indicando que possivelmente Romero não se empenhou em ler Pedro Américo com a devida atenção. Romero teria divergido de Pedro Américo em muitos pontos, e, principalmente, da tese de que a liberdade de investigação científica é herdeira da liberdade de criação artística, isto é, de que os filósofos naturais da Revolução Científica eram herdeiros dos grandes artistas do Renascimento (BARROS, 2006).

\section{Filosofia natural e ciências físicas: a ciência como atividade filosófica no pensamento de Pedro Américo}

Quando trata das ciências naturais, Pedro Américo não as nomeia somente como "ciências", ou Scientia, mas também como Filosofia Natural. Às vezes fala em ciências naturais, ciências experimentais, mas no título de sua tese faz questão de chamar-lhes de Filosofia Natural ${ }^{3}$. Por quê? Por hábito ou costume? Por que era essa a prática em sua época? Em parte, sim, mas acreditamos em outras razões, isto é, pensamos que, ao fazê-lo, há uma tomada de posição por parte do autor. Ele se posiciona tanto intelectualmente, quanto institucionalmente. O grande debate de Pedro Américo é contra os materialistas, positivistas e empiristas, como veremos mais à frente. Continuar tratando as ciências físicas como Filosofia, portanto, é uma forma de reclamar autonomia e liberdade espiritual para os investigadores da natureza. Se as ciências físicas são "Filosofia", então não se reduzem à técnica, não estão circunscritas aos interesses utilitários e instrumentais que estimam o conhecimento somente na medida em que pode ser "útil", que pode servir como um meio para o progresso, a indústria, o desenvolvimento da base material das sociedades modernas.

\footnotetext{
2 Como podemos ver pela notícia da edição do número 9, "Anno I", de 1870, do A Comédia Social: Hebdomadario Popular Satírico: 0 Sr. Pedro Américo de Figueiredo e Melo não é nome novo e desconhecido entre nós: ao contrário sua reputação de homem talentoso e instruído está por tal fórma fundada que dispensa qualquer nova prova. Apezar, porém, da opinião geral, o Sr. Dr. Américo quiz dar mais uma eloquente e inequívoca demonstração de seu merecimento. No dia 22 do corrente, dia em que tomou posse, como professor das artes, esthetica e arqueologia na academia das belas-artes, S. S., perante S. M. o Imperador e um numeroso e distincto concurso de cavalheiros, abrilhantado por muitas senhoras, proferio um notável discurso, provando não só as vantagens que às artes traz a cadeira ultimamente creada, como ainda sua vasta erudição. A Comédia Social, enthusiasta de tudo quanto é grande e esperançoso, felicita cordialmente o Sr. Dr. Pedro Américo, dizendo-lhe que o paiz muito espera de seus esforços em prol das belas-artes tão despresadas entre nós (A COMÉDIA SOCIAL, 1870, p. 3).

${ }^{3}$ Tese defendida em 13 de janeiro de 1869 em Bruxelas com o título La Science et les Systémes, questions d'Histoire et de Philosophie naturelle.
} 
Isso não quer dizer que a ideia de uma separação histórica entre a Filosofia e suas "descendentes", as ciências particulares, fosse estranha ou nova. Embora posterior à tese de Pedro Américo, podemos nos utilizar de um trecho de $A$ Finalidade do Mundo (1895), de Farias Brito, para abordarmos o "problema da separação". A Filosofia teria sido a mãe das ciências, ou, na imagem de Boltzmann, a "Rainha das Ciências" (BOLTZMANN, 2004); uma mãe que ao criar seus filhos e filhas para o mundo, como geralmente se diz, os vai "perdendo" aos poucos. Para Farias Brito:

Quanto à física o processo [de desmembramento das ciências particulares da Filosofia] foi lento e contínuo e ainda no tempo de Platão e Aristóteles quando a Antiguidade atingiu seu mais alto grau de desenvolvimento, a filosofia era a ciência universal, compreendendo a metafísica, a física, a psicologia, a moral, etc. Era, como se costuma dizer e refere Ribot, a ciência do homem, da natureza e de Deus. Isto continuou assim durante toda a Idade Média, e entrou mesmo pela Idade Moderna, tanto assim que ainda a física de Newton é exposta sob o título de Principia philosophiae. Exatamente a mesma coisa se dá com Descartes. Mas hoje ninguém desconhece o que é a física, nem há quem seja capaz de negar o seu caráter de ciência independente [...] (FARIAS BRITO, 2012, p. 49).

Apesar do status da Física como "ciência independente", que Farias Brito pontua, toda ciência particular seria, na concepção de Pedro Américo, atravessada por problemas universais, e em todo campo do trabalho científico residiriam questões filosóficas.

A recusa da separação entre Filosofia e Ciência, que Pedro Américo realiza ao chamar a ciência de Filosofia Natural, e ao conceber que seu valor reside na busca da verdade, objetiva expor e desconstruir as contradições do positivismo, que segundo Pedro Américo, nos prende a uma concepção materialista e empirista da ciência. Para Pedro Américo, o problema do positivismo não está somente em sua inconsistência epistemológica ou em seu malabarismo lógico-semântico, mas em seus valores. ${ }^{4}$ Retirar das ciências o seu espirito filosófico é um golpe tecnicista que enfraquece a própria pesquisa científica, colocando-a como refém de propósitos utilitários. Ao prender o cientista à esfera dos problemas positivos, da atitude instrumental e dos interesses utilitários, se lhe corta as asas da livre especulação, da criação artística, da investigação desinteressada, impedindo que a ciência seja uma forma de vida, constrangendo-a a uma forma para a vida, não um fim em si mesmo, mas um meio para o ideal positivista de "ordem e progresso".

O que Pedro Américo quer é reclamar para o filósofo natural a mesma liberdade de que dispõem os artistas. Seu modelo ou paradigma ${ }^{5}$ de cientista não é o homem de laboratório produzido pela modernidade, o técnico, o espírito prático da indústria, o inventor empreendedor, mas o homem do Renascimento, bem como seu modelo de "progresso" não é a sanha desenvolvimentista e tecnicista, mas a criação artística, "o espírito moderno é devedor dos progressos dos artistas do Renascimento, que defendiam a liberdade intelectual, e a ciência nos pareceu o fruto da aplicação dessa liberdade em busca do verdadeiro" (MELO, 1999, p. 129-130).

Antes mesmo do positivismo, não somente em sentido histórico quanto filosófico, o lluminismo já havia consolidado, em todo mundo, uma concepção instrumental das ciências como ferramentas por meio das quais poderíamos resolver nossos problemas materiais e alcançar o desenvolvimento econômico e a prosperidade social. Uma dicotomia - que defen-

\footnotetext{
4 Para Fábio D'Almeida Lima Macial (2016, p.132) em “O jovem Pedro Américo, entre Arte, ciência do Belo e um outro nacional", tese de doutorado apresentada à Escola de Comunicações e Artes da Universidade de São Paulo, Pedro Américo lutou "oficialmente" e "continuamente" contra o positivismo no Brasil.

${ }^{5}$ Sem conotação kuhniana direta. Nos referimos a paradigma como peça matriz, o ideal, o modelo de perfeição, que por ser uma idealização, talvez jamais se concretize, funcionando como um horizonte, um norte, em direção ao qual devemos nos mover sem que o fim almejado possa ser plenamente alcançado.
} 
demos ser uma falsa dicotomia - entre verdade e utilidade impulsionou a degradação pública do ideal de "ciência desinteressada" ameaçando concretamente a noção de "pesquisa básica". "A defesa da utilidade dos estudos da natureza transformou-se em lugar-comum durante o alto Iluminismo" (KURY, 2004, p. 109). Para Kury (2004) as "luzes luso-brasileiras" foram marcadas desde meados do século XVIII por essa atitude que consistia em detratar a "pesquisa diletante" desinteressada, e favorecer a investigação utilitária voltada para a aplicação. No Brasil do século XIX, diversos cientistas, como Lias e Morize, do Observatório Nacional, sofreram com a falta de recursos e de prestígio da investigação fundamental, e tiveram de defender o valor e a importância estratégica da pesquisa básica (VIDERIA, 2012; SILVA, 2019).

É nesse contexto histórico de disputas intelectuais, embate de escolas filosóficas e tensões sociais e institucionais, que devemos inserir a defesa que Pedro Américo faz da liberdade da Filosofia Natural. Disputar uma concepção de natureza da ciência é não somente reivindicar a primazia de determinados valores epistêmicos e morais, mas literalmente concorrer por recursos, capitais, espaços sociais, políticos e institucionais. Pedro Américo sustenta que "para permanecer fiel ao método científico, é necessário garantir que a pesquisa da verdade seja livre de toda ideia preconcebida e de toda pressão exterior. Tal é a condição do progresso da ciência" (MELO, 1999, p. 131). Nesta simples passagem algumas características da concepção de natureza da ciência de Pedro Américo podem ser esboçadas:

1. Veritismo: O objetivo da pesquisa científica é buscar a verdade, isto é, buscar se aproximar da compreensão da natureza última da realidade.

2. Liberdade: Para alcançar seu objetivo, a ciência deve gozar de uma liberdade radical, tanto espiritual quanto prática.

3. Autonomia: O exercício da liberdade requer autonomia, tanto intelectual, quanto política, social e institucional. A ciência não deve ser pressionada e constrangida por forças e interesses externos, sejam religiosos, políticos, econômicos, ou de qualquer outra espécie.

4. Desinteresse ou "interesse interno": Autonomia pressupõe que os interesses da ciência são autojustificados, interesses internos, epistêmicos, intelectuais, filosóficos, estéticos, e não externos, o que atentaria contra sua autonomia.

5. Progresso interno: Sendo a ciência livre, autônoma e desinteressada, seu progresso não pode ser avaliado conforme parâmetros estrangeiros e critérios externos. Avaliar a fecundidade de uma teoria por sua possibilidade de aplicação e a beleza de uma criação científica pelas utilidades produzidas a partir de seus princípios básicos, seria uma perversão da investigação natural. As condições do progresso científico não são dadas por demandas práticas, mas por seu ambiente interno de livre criação.

O veritismo de Pedro Américo, combinado com outros valores, como liberdade, autonomia, desinteresse e progresso interno, fica bem evidente quando ele defende que "buscar a verdade independentemente de toda influência estranha ao método e expor o resultado da pesquisa, seja qual for", é de fato "o que constitui, ao mesmo tempo, a liberdade no estudo da natureza e o livre ensino das ciências naturais" (MELO, 1999, p. 133-134).

Poderíamos dizer que essa concepção de ciência, defendida por Pedro Américo, é internalista e "purista", e mesmo que sustenta uma espécie de Torre de Marfim, em que cientistas desinteressados e diletantes, alheios ao mundo, buscam a verdade como seres angelicais, no etéreo, e não como atores sociais, históricos, no mundo. Mas acreditamos que essa seria uma imagem caricatural de Pedro Américo e de sua filosofia. Pedro Américo está jogando o jogo, 
fazendo política, advogando em prol da imagem de ciência que o interessa. O debate é filosófico, metafísico, intelectual. Mas quando sistemas de mundo, doutrinas, ideologias, cosmovisões, concepções de ciência, cultura e sociedade estão em disputa, o que está sendo disputado são modos de vida, de organização social, de divisão do trabalho.

Quando Pedro Américo defende a ciência das influências externas ele está fazendo justamente o contrário de apartá-la da vida social e política - por reconhecer sua natureza social e a existência efetiva de tais pressões é que tal defesa seria necessária. Pedro Américo é um artista, em uma complexa rede de mecenato. Quando toma os homens do Renascimento como modelos, modelos que são artistas, artífices, inventores, filósofos naturais, artesãos, mecânicos, "engenheiros", ele, que vive na própria pele a condição de artista de encomendas, bolsista, competidor de feiras e concursos, conhece bem os limites do "desinteresse" do criador, do livre pensador, do homem do Renascimento. Tal desinteresse é uma atitude, um valor, uma forma de vida. Como ator social, no entanto, esse personagem sabe que é uma peça em um tabuleiro cheio de tensões e interesses diversos, em que as torres não são de marfim.

Reclamar por uma ciência livre das pressões externas faz parte de uma estratégia defensiva, de quem se vê na constante necessidade de reforçar as muralhas e fortalecer as bases, para que as pressões exteriores não venham a derrubá-las, reduzindo os espaços internos, onde alguma liberdade de trabalho é possível. Em momentos menos defensivos, a busca por liberdade e autonomia da ciência constituem elementos de uma estratégia expansiva, por meio da qual se busca ampliar os espaços de criação, aumentar a influência institucional e política da comunidade de praticantes de ciências e garantir melhores condições de trabalho, além, é claro, no plano epistemológico, de promover uma "blindagem intelectual", para que os membros da comunidade possam se dedicar à pesquisa sem que tenham que "prestar contas" de seus rumos e resultados com tanta frequência e rigor. Se os espaços internos são eliminados ou passam a ser determinados por interesses impostos externamente, os únicos quadros a serem pintados, esculturas a serem feitas, teorias e experimentos a serem criados, são aqueles encomendados ou aprovados pelos agentes externos.

Pedro Américo parece bem ciente de que os renascentistas viviam nesse "campo de batalhas", em meio a tensões, competições e disputas. Cediam em alguns trabalhos, perdiam algumas casas, agradavam seus mecenas, para avançar algumas casas duas ou três jogadas depois. Como atores sociais e históricos de carne e osso, os renascentistas, por mais sublimes e abstratos que fossem seus ideais, eram peças de um jogo complexo, e garantir boas encomendas, uma posição na rede de mecenato, status, eram movimentos necessários, previstos pelas regras do jogo. No entanto, assim como a Polis pode explicar por que existem filósofos e oradores, mas não determinar a substância e o gênio da obra de Sócrates, as condições sociais e históricas do Renascimento são necessárias para compreendermos suas realizações, mas insuficientes para entendermos seu brilhantismo. As maiores invenções, conquistas e criações do Renascimento não podem ser o simples resultado das demandas crescentes por obras de arte, da competição dos artistas, inventores e artífices, da circulação de ideias e saberes. Tudo isso deve entrar na explicação, mas nada disso, isoladamente, pode ser a explicação.

A simples demanda da Igreja, das aristocracias, dos mecenas, não pode explicar o sfumato de Leonardo, o olhar de Monalisa, os volumes do Davi de Michelangelo, e nem o telescópio de Galileu. ${ }^{6}$ Criadores como Michelangelo, Rafaelo, Leonardo e Galileu, até mesmo o

\footnotetext{
${ }^{6}$ Não queremos confundir o Renascimento com a chamada Revolução Científica, e nem incluir Galileu e seus contemporâneos dentre os renascentistas, e nem pensamos que Pedro Américo o tenha feito. Frisemos, portanto, tal ponto, para que nenhum mal-entendido tenha lugar de prosperar nessa matéria. Contudo, ao que nos parece, e o que é plenamente justificável, é que em Pedro Américo, o filósofo natural da Revolução Científica é visto como uma espécie de herdeiro cultural do Renascimento. A liber-
} 
Galileu cortesão de Biagioli, têm que ambicionar algo além do que uma boa renda ou uma aposentadoria voluptuosa, devem entregar mais do que a própria encomenda. Sem isso não haveria "Davi", ou a "Madona das Rochas", nem "O Ensaiador". É certo que a ciência ou arte "desinteressada" é um valor e não um fato. Criadores, como o próprio Pedro Américo, possuem interesses econômicos, profissionais, pessoais, estão em busca de melhores financiamentos, bons contratos, posições profissionais privilegiadas, mas em último caso, seus interesses também devem ser genuinamente filosóficos e científicos, epistêmicos e estéticos, ideológicos e metafísicos, doutrinários e religiosos. Em grande parte, são tais interesses que nos ajudam a compreender o "frenesi", a paixão, o ímpeto criativo, a determinação meticulosa, a inovação técnica, e mesmo o elemento de vaidade intelectual, em suma, a ambição espiritual, dos criadores.

Se Pedro Américo, artista, sustentado por encomendas e bolsas, toma os renascentistas por ideal, e pensa na ciência como uma atividade filosófica, livre, de busca da verdade, não o faz como um proselitista da Torre de Marfim, mas como alguém atento às tensões de seu campo e atento aos desafios de seu tempo. O Brasil de Pedro Américo é amplamente influenciado pelo ambiente intelectual francês, e identifica no positivismo comteano o fruto maduro do espírito científico desenvolvido em França. Nesse ambiente, ou os cientistas lutam por algum espaço de livre criação, ou são reduzidos a produtores de encomendas de utilidades práticas. Em toda Europa o positivismo por um lado, o instrumentalismo por outro, avançavam sobre o flanco cultural, conquistando terreno e angariando adeptos. França, Inglaterra, Alemanha. Nos Estados Unidos, o espírito pragmático se formava e expressava sua herança britânica. No Brasil, o positivismo alcançaria ares de religião.

Como personagem do século 19, Pedro Américo estava vivendo e participando de profundas transformações intelectuais, dentre as quais a transição da Filosofia Natural para Física Teórica, que experimentava seu processo de institucionalização. Segundo, diversos fatores, dentre os quais fatores externos, como a divisão social do trabalho, a formação acadêmica e a organização do mundo econômico, influenciavam a separação entre Filosofia e Física. Até aqui podemos compreender que Pedro Américo reagia a esses dois processos. Por último, o positivismo buscava combater a Filosofia, sobretudo a Metafísica, embora também fosse uma "posição filosófica".

Farias Brito, em Finalidade do Mundo lembra que Comte "se apresentou como o destruidor da metafísica" (FARIAS BRITO, 2012, p. 19). Para o filósofo, tamanha era a violência da inquisição positivista contra a metafísica, que a "fórmula política" do positivismo seria a "ditadura científica" (FARIAS BRITO, 2012, p. 182).

Pelas palavras de Farias Brito podemos ver o quanto as táticas de debate positivistas eram intensas - e sem dúvida as reações antipositivistas foram igualmente fortes. Talvez essa "intensidade" justifique um pouco a caricatura. Tendemos a ver como extremistas aqueles que, no debate público, parecem não respeitar normas tácitas da comunidade, exagerando tanto no tom, que seus debates se transformam em verdadeiros combates. Geralmente como reação, os

dade de pesquisa do filósofo natural da Revolução, ainda que exercida em um 'campo de tensões e disputas', é como uma conquista cultural que remonta à liberdade de criação dos artistas do Renascimento, que também buscavam criar livremente, ainda que imersos em uma complexa rede de relações sociais própria do mecenato renascentista. Para saber mais sobre tal relação, recomendamos a tese de doutorado de $A$ arte como princípio educativo, de Francisca de Gois Barros, trabalho para o qual já chamamos a atenção nesse artigo.

7 Para uma compreensão distinta do positivismo, ver Thomas Glick: “O positivismo não é uma filosofia estrito senso, mas é principalmente um conjunto de princípios gerais apropriados por indivíduos ou grupos para legitimar objetivos ideológicos intelectuais específicos ou políticos (Glick, 1989). Um dos problemas historiográficos referentes ao positivismo na América Latina tem sido uma muito rígida dicotomização entre variações do positivismo comteano e spenceriano (GLICK, 2003, p. 181). 
atacados costumam igualmente radicalizar para o lado oposto, a fim de se defenderem. Talvez por isso, por se sentir atacado e ameaçado pelo positivismo crescente, Pedro Américo tenha ido para o outro extremo da balança, defendido a Filosofia Natural, a busca da verdade, a liberdade e o desinteresse.

O percurso intelectual de Pedro Américo na Europa não deve ser visto como mais um caso banal para a época, quando era muito comum que os brasileiros mais abastados realizassem parte de seus estudos no velho continente. No caso de Pedro Américo, não podemos dizer que ele pertencesse à aristocracia brasileira. Ele dependia da rede de mecenato da corte imperial. O que é mais significativo, no entanto, é o que Videira (2005) pontua em A Filosofia da Ciência sobre o signo dos science studies. Não podemos compreender o conhecimento científico ignorando o contexto histórico e social de seu local de produção. "Pedro Américo sugere que a compreensão do que é a ciência requer a compreensão das características nos locais em que ela é feita, além, é claro, das condições necessárias para que a ciência seja feita daquele modo específico" (VIDEIRA, 2005, p. 78). Pelas características do ambiente intelectual predominante no Brasil àquela época, talvez Pedro Américo não tivesse produzido a sua obra se tivesse permanecido por aqui.

O que o percurso de Pedro Américo na Europa tem a nos dizer sobre o Brasil? Por que tal percurso não é de interesse somente biográfico, para aqueles que pretendem compreender sua trajetória, como também sociológico e histórico, para os que se perguntam pelo contexto intelectual brasileiro naquele período? Por que Pedro Américo estuda, escreve e publica Filosofia da Ciência na França e na Bélgica, e não no Brasil? O próprio autor responde em sua obra:

Se este livro tivesse sido escrito no Brasil, faltar-lhe-ia certamente cor local, pois nenhuma das questões que eu abordo com alguns desenvolvimentos é tratada aqui sob um ponto de vista nacional; por isso, quem o lesse sem pensar nesse fato - que a situação moral e intelectual da Europa difere bastante da nossa -, o acharia, sob muitos aspectos, algo vazio e sem sentido. Mas, é preciso, então, escrever um livro para provar que a ciência é livre? Para provar que temos por porventura uma alma imaterial, ou então que o homem é um animal racional? Quem jamais dentre nós [os brasileiros] disse o contrário? Eis o que parece estranho e verdadeiramente fora de propósito. Mas, para quem quer que tenha acompanhado o desenvolvimento histórico da ciência e conheça a situação atual dos espíritos na Europa, todas essas questões se apresentam como outros tantos problemas cujas soluções, constantemente impugnadas por espíritos exclusivistas, merecem sempre ser renovadas no sentido mais verdadeiro e imparcial (MELO, 2001, p. 3).

Ao afirmar que sua obra não encontraria leitores no Brasil, Pedro Américo coloca em destaque algo que, hoje, parece evidente: Não havia, naquela ocasião, em terras brasileiras, uma rede de circulação de saberes e discussão de ideias em Filosofia da Ciência - disciplina muito nova, cuja origem também pode ser datada na primeira metade do século XIX e localizada na Grã-Bretanha, com William Whewell. A Filosofia Natural, ou se bem o quisermos, nem a filosofia e nem a ciência, encontravam-se plenamente institucionalizadas no Brasil. O Brasil não participava do debate filosófico acerca do valor da ciência. Aliás, se tomarmos as palavras de Silvio Romero a sério, o Brasil não possuía nem mesmo qualquer tradição filosófica: "Póde-se afirmar, em virtude da indagação histórica, que a filosofia, nos três primeiros séculos de nossa existência, nos foi totalmente estranha" (ROMERO, 1878, p. 1).

Em seguida veremos os grandes problemas de Pedro Américo (1): a atitude transcendente e racional do pensamento científico, sintetizada em seu "racionalismo experimental" e (2) relação entre Ciência e Liberdade. 


\section{A ciência como conhecimento sistemático que transcende o "mundo sensível"}

Pedro Américo assume um racionalismo filosófico forte, e o combinará, sem grandes dificuldades epistemológicas, com o método experimental da ciência moderna. “Em uma palavra, no método experimental como em tudo, o único critério real é a razão" (MELO, 1999, p. 102). Assim, a ciência deve ser experimentalista sem ser empirista. O racionalismo, portanto, não dever ser confundido com qualquer espécie de "abstracionismo" ou "teorismo". Há lugar para a observação e para a experiência no racionalismo, e seu lugar é como o de uma coluna fundamental, sem o qual um novo patamar de conhecimento não pode ser edificado. Nenhuma coluna, no entanto, por mais forte e necessária que seja, pode se erguer em bases movediças. A coluna deve partir de um alicerce. Na teoria do conhecimento científico de Pedro Américo, o fundamento não pode ser outro senão a razão. Assim, como em uma construção arrojada, razão, observação e experimentação formam um sistema: "a ciência é um conjunto de conhecimentos verdadeiros e certos ou, como dizia Ampére: 'um grupo de verdades demonstradas pela razão, reconhecidas pela observação ou percebidas pela consciência"' (MELO, 1999, p. 3).

Para Pedro Américo, o racionalismo da Filosofia Natural fica evidente quando analisamos as conquistas do sistema copernicano. A nova teoria negava que a resposta para a compreensão da natureza pudesse ser dada por nossa experiência imediata do mundo sensível, pelo que os olhos podiam ver e os demais sentidos experimentar. A concepção de mundo de Copérnico superaria o empirismo sensualista. "A hipótese de Copérnico suporia que os sentidos nos enganam enormemente [...]. Quem a partir de agora sustentará o mundo? Somente a Razão" (MELO, 1999, p. 49-50). Pedro Américo defende um novo racionalismo, que supere o empirismo sensualista sem prescindir do experimentalismo rigoroso. A experimentação científica, enquanto expressão da razão, é uma conquista da Filosofia Natural, mas o empirismo que nos prende ao mundo sensível, tornando-nos reféns dos sentidos, impede a razão de perscrutar os domínios mais profundos da realidade. Copérnico e Galileu são os grandes exemplos de tal racionalismo:

[...] A humanidade é ameaçada de morte! Quem a salvará? Copérnico, isto é, o maior de seus contraditores. Eis o fato que mais perturbou o Renascimento. No momento em que a observação é unicamente recomendada, num tempo em que, exausto de mexer com o pensamento no vazio, não quer mais crer senão no que vê, Copérnico vem desmentir o testamento dos sentidos. [...] [Copérnico] quer subjugar o mundo sensível, as percepções materiais, o atestado indiscutível dos olhos! Declara o grande homem que tudo isso não passa de matéria que deve servir de degrau ao gênio para se elevar mais alto; nada mais. (MELO, 1999, p. 48). [Grifo nosso].

A ciência só prospera na liberdade, a começar pela liberdade da razão. E do que ela deve se libertar? Da autoridade da fé, do peso da tradição e do império dos sentidos. Os oponentes de Pedro Américo são bem delimitados. O "fanatismo contra a liberdade" provém (1) do dogma paralisante que submete a razão aos ditames da "Doutrina", (2) da falta de ímpeto e coragem para criar um pensamento novo, original, submetendo-se assim à autoridade da tradição e (3) da ação dissolvente do materialismo positivista que serve de palco para obscurecer ou derrubar a liberdade e a razão. Para Pedro Américo, o sensualismo moderno defende com "estranho fanatismo" a "hipótese materialista" dos positivistas, atacando a liberdade da razão, subordinando-a aos limites estreitos da "positividade", buscando tornar sem sentido a busca pela verdade (MELO, 1999, p. 89). 
Mais tarde Farias Brito veria essas mesmas características no positivismo: Por um lado o positivismo recusa a busca da verdade ao renunciar ao absoluto e se apresentar como um movimento relativista de "renovação do cepticismo", por outro, "se confunde praticamente com o materialismo", ao pensar que só o fenômeno é positivo e que o fenômeno é puramente material (FARIAS BRITO, 2012, p. 186; 209).

Ao negar o sensualismo materialista dos positivistas, Pedro Américo busca outros caminhos, como o de um "racionalismo experimental", capaz de combinar a razão teorética com o método experimental. Com Copérnico, cujo sistema é racional, intelectivo, teríamos nos afastado do sistema aristotélico-ptolomaico, de natureza sensível. Esse teria sido o primeiro passo rumo à nova ciência. Para tal passo, a liberdade de espírito seria fundamental. $O$ autor defendeu uma correlação entre a liberdade na arte e a liberdade na ciência. A liberdade artística dos mestres do Renascimento abriu caminho para a liberdade científica dos filósofos naturais que promoveram aquilo que descontinuístas como Alexandre Koyré chamam de "Revolução Científica" (KOYRÉ, 2006).

De certo modo o pensamento de Pedro Américo antecipa o de Koyré, pois ambos pensam a "Revolução Científica" como uma revolução filosófica. O que Copérnico faz, e Galileu leva adiante, é uma retomada da metafísica pitagórico-platônica, do projeto de matematização da física e geometrização da natureza. Pedro Américo não utiliza tais expressões, mas enfatiza o "racionalismo experimental", a importância do pensamento matemático na superação de um sensualismo limitador. A Filosofia Natural Matemática - posteriormente chamada de "ciência moderna" - rompe com a física aristotélica, se afasta do "Mundo sensível", e edifica teorias por meio das quais podemos descobrir uma ordem subjacente à natureza, compreender como o mundo natural é matematicamente ordenado e como aquilo que é sensível é o resultado de leis puramente intelectivas.

Pedro Américo pensa que o telescópio de Galileu, o perspecillum, passa pelo que poderíamos chamar de ascensão epistêmica, deixando de ser um equipamento utilitário para se tornar um instrumento científico. O telescópio de Galileu está impregnado de teoria, ou, meIhor dizendo, é a corporificação de pressupostos e objetivos filosóficos (MELO, 1999, p. 96). Mais uma vez, é notável a aproximação que podemos fazer entre o pensamento de Pedro Américo e o de Koyré, para quem os instrumentos científicos são a materialização de princípios teóricos, ou, por assim dizer, princípios teóricos encarnados (KOYRÉ, 2006). ${ }^{8}$

A Filosofia Natural, isto é, a ciência moderna, é, para Pedro Américo, marcada pela matematização. A matemática não possui valor meramente instrumental. Qualquer que seja a ontologia da física, a matemática, como expressão da razão, tem algo a nos dizer sobre a natureza última da realidade. Por isso os instrumentos científicos, como o telescópio de Galileu, antes de existirem no mundo sensível, têm sua realidade descortinada no mundo intelectivo: "um geômetra isolado, perdido em suas abstrações, lança no mundo ao qual de certa forma ele está alheio, descobertas inestimáveis; os sábios da especialidade recebem-nas e as aplicam no aperfeiçoamento dos instrumentos de ótica mais precisos" (MELO, 1999, p. 97).

Na visão de Pedro Américo, Galileu seria uma ponte entre essas duas idealizações. Ele encarnaria tanto o filósofo natural platônico, o físico matemático mergulhado no mundo das

\footnotetext{
8 Videira, em As descobertas astronômicas de Galileu nos ajuda a compreender a complexa situação de Galileu como ator político e social. De fato, Galileu desejava - e o faria - romper com o praticismo utilitário, o que o levaria a utilizar o perspicillum para observar os céus. No entanto, Galileu precisava de financiamento para levar a cabo suas pesquisas e se manter e desejava melhorar sua posição na Universidade de Pádua. Como estratégia, tentou demonstrar aos senhores de Veneza o alcance utilitário, por exemplo, náutico e bélico, do novo instrumento. Em Veneza os negócios não prosperaram, levando-o aos Médici em Floresça (VIDEIRA, 2009, p. 52).
} 
abstrações, quanto o especialista, imberbe no mundo das oficinas, dos artesãos, dos engenheiros. Assim, teria sido capaz, como filósofo natural, de aplicar os mais abstratos conceitos teóricos para materializá-los na forma de um instrumento científico. A inovação de Galileu é revolucionária. Com ele a metafísica experimental ganha nova vida. É possível agora, mais do que nunca, filosofar com instrumentos, elaborar hipóteses, construir sistemas teóricos, criar modelos abstratos, e testá-los, filosoficamente, por meio de rigorosos processos de observação, como a observação astronômica telescópica, e por meio de processos controlados de experimentação, como o plano inclinado.

A Philosophiæ Naturalis não aceita a dicotomia caricatural entre o filósofo puro, perdido em abstrações, e o cientista, capaz de realizar observações e experimentos. Práticas de observação e intervenção no concurso dos eventos naturais remontam mesmo à antiguidade, mas com Galileu tanto a matematização quanto a experimentação são potencializadas, e se tornam bases fundamentais do método filosófico de inquirição do mundo com a pretensão ontológica de se chegar à compreensão da natureza última da realidade.

O que Galileu vê na superfície lunar ou nas manchas solares não se atém a fenomenologia da física. Na aparência dos sistemas observados, na experiência sensível, no mundo das sombras, existem traços legíveis de princípios físicos profundos cuja apreensão sensível é impossível. Tais princípios são intelectivos, objetos da razão. Nas entrelinhas dos eventos naturais podemos ler os códigos eternos da estrutura física do mundo. Se o livro da natureza está escrito em linguagem matemática, as verdades matemáticas, as formas matemáticas puras, não se encontram ocultas, "enroladas" ou escondidas em frações inacessíveis do real, elas deixam suas assinaturas nos fenômenos, suas marcas, seus selos, nas aparências - as superfícies carregam as impressões, as assinaturas, das profundezas. Os leigos podem ver pedras caindo, astros se movendo, a sucessão dos dias e das estações, mas os filósofos naturais veem figuras geométricas e relações numéricas. Por meio da razão podemos ler o livro da natureza, mas por meio da observação e da experimentação, podemos ver como a realidade observável, o mundo sensível, pode ser matematicamente decodificado, revelando uma estrutura fundamental dotada de unidade, ordem e harmonia. A observação e a experimentação revelam que a ordem matemática subjacente, o códex matemático intelectivo, aflora à superfície na organização aparente do mundo sensível. Se a matemática é o alfabeto com o qual a natureza foi escrita, a superfície da lua e do sol, o movimento dos astros, as órbitas dos planetas, a queda dos corpos, são o texto escrito, capítulos da prosa - ou da poesia - assim composta. As verdades matemáticas básicas podem ser objeto exclusivo da intelecção, mas as histórias narradas no livro da natureza podem ser lidas por meio da observação e da experimentação.

Para Pedro Américo, a falsa dicotomia entre a razão, que nos leva a especulações e abstrações, e a ação experimental, que nos atém aos dados sensíveis, distorce uma harmonia subjacente entre as duas atitudes. Não há conflito entre experimentalistas e racionalistas, por que não há experimento que não seja expressão da razão mesma. Esse é o sentido de seu conceito de "racionalismo experimental". Pedro Américo concebe o filósofo natural como aquele que, se libertando dos sentidos, dos dogmas, da influência da religião, e dos mais variados interesses externos, busca a verdade por meio da razão. A razão, por sua vez, além da introspecção, da contemplação, da reflexão e da análise, nos conduz ao planejamento e execução de observações e experimentos. Assim, a experimentação, no pensamento de Pedro Américo, não é uma prática empirista, mas racionalista ${ }^{9}$.

\footnotetext{
${ }^{9}$ Silvio Romero, em A Philosophia no Brasil, obra em que critica duramente o pensamento filosófico de Pedro Américo, considera que a compreensão de Pedro Américo da ciência de seu tempo é equivocada. Para Romero "O nosso autor fantasia que a sciencia
} 
O experimento é expressão do engenho da razão, ele é planejado, executado e interpretado conforme princípios racionais. "Observar é procurar ver nos fatos tudo o que eles nos podem oferecer deles mesmos, sob todos os ângulos e em todos os detalhes", já experimentar é "produzir ou modificar artificialmente, e a vontade, os fenômenos a se estudar"; mas como experimentar seria possível sem uma razão teorética? A experimentação, para Pedro Américo, "supõe, ainda mais que a observação, uma atividade intelectual dotada de certos poderes e de certas leis logicamente anteriores à experimentação" (MELO, 1999, p. 11). Os sentidos não são suficientes como fontes de conhecimento. Mas isso não nos afasta do experimentalismo, somente do empirismo, do sensualismo grosseiro, do materialismo limitado. O experimentalismo, guiado pela razão, não se reduz ao empirismo, anti-racional. O mundo não nos pode ser dado a não ser pela razão. "Ora, se o testamento dos sentidos não basta para estabelecer cientificamente os fatos, o que falta acrescentar? Aparentemente juízos, isto é, uma operação consciente da razão" (MELO, 1999, p. 99).

Pedro Américo defende seu "racionalismo experimental" e elege representantes de peso para sua posição, ao apresentar Copérnico e Galileu como expoentes da razão no combate ao sensualismo, ao empirismo e ao positivismo, que apesar de suas diferenças, são, para nosso autor, variadas expressões do materialismo, que ameaçam o lugar que a razão deve ocupar, não somente nas ciências da natureza, mas na cultura de modo geral. Apesar de Newton ser outro filósofo natural marcado pela matematização da física, há um elemento no pensamento filosófico newtoniano combatido pelo racionalismo de Pedro Américo. Quando Newton declara Hypotheses non fingo (NEWTON, 1999, p. 943) ${ }^{10}$, vaticinando que as hipóteses não têm lugar em seu Philosophiae naturalis principia mathematica, isso parece soar, a Pedro Américo, como um interdito à razão, uma limitação da liberdade plena de que a razão pura deve gozar na livre criação dos sistemas físicos do mundo. A reação de Pedro Américo é forte:

\footnotetext{
A história da verdade está, entretanto, longe de justificar essa opinião (o combate absoluto às hipóteses) e enquanto nos mostra os perigos do método hipotético, faz-nos ver que as descobertas que mais honraram o espírito humano não eram, inicialmente, mais do que uma vaga suspeita da inteligência, uma previsão ainda incerta e que ultrapassava os fatos observados (MELO, 1999, p. 104).
}

\footnotetext{
moderna está toda eivada de empirismo, e gasta o $4^{\circ}$ e último capítulo de seu livro, quase exclusivamente, a castigar-lhe os desvarios, e a proclamar a soberania e as excelências da razão. Elle é partidário do methodo dito racional. Ora, isto é hoje um ponto de vista anachronico; a sciencia de agora, em suas eminencias, nas mãos dos nobres sectários do realismo naturalista das escolas inglesa e allemã, nada tem de empírica" (ROMERO. 1878, p. 57). A despeito de toda a erudição de Romero, não podemos deixar de apontar o que parece ser um entendimento, no mínimo, bastante problemático do autor. Dizer que no século XIX a ciência nada tinha de empírica pode até mesmo ser um desvario. Para isso a contextualização histórica é imprescindível para a reflexão filosófica. Quando situamos a crítica de Romero sob o pano de fundo dos movimentos intelectuais e científicos do século XIX, verificamos sua inconsistência. O século XIX fora marcado por uma abordagem positivista e empirista, que culminaria no século XX nas escolas do neopositivismo e do empirismo lógico. Romero avança em seu texto criticando Pedro Américo por ignorar que a ciência se utiliza tanto da razão quando da experimentação. Vimos, todavia, que é justamente isso o que Pedro Américo defende por meio do conceito de "racionalismo experimental".

${ }^{10}$ Cabe pontuar que a sentença Hypotheses non fingo aparece pela primeira vez no Escólio Geral da segunda edição dos Principia, de 1713. Em inglês a sentença aparece em 1729, na tradução de Andrews Motte, como "I frame no hypotheses". Em "The first english version of Newton's Hypotheses non fingo", I. B. Cohen pontua que Newton não aprovou a tradução de Motte. Para saber mais acerca de tal discussão, ver Cohen, 1962. Na tradução de Cohen do Principia (1999), a sentença que lemos é"I do not 'feign' hypotheses", em que "frame" é substituído por "feign", como tradução de "fingo". Não queremos, aqui, ensaiar exercícios filológicos e nos aventurar por paragens semânticas e etimológicas. Notamos, apenas, que tal tradução nos permite pensar que Newton não estava negando que construía ou elaborava hipóteses, mas sim afirmando que não se utilizava de hipóteses para "forjar", "simular" ou mesmo "fabricar" resultados. Assim, o problema não seria a construção de hipóteses, mas a "fabricação" de resultados físicos convenientes (O velho recurso de "Salvar as aparências") por meio de hipóteses. Para saber mais sobre as hipóteses na filosofia de Newton, ver Cohen, 1969.
} 
Pedro Américo reconhece os "perigos do método hipotético", dentre os quais, a tergiversação infértil de uma especulação alheia ao mundo. A razão, em Pedro Américo, é o fundamento, o alicerce, mas não nos esqueçamos de que as colunas são dadas pela experimentação. Assim, a razão deve elaborar hipóteses de modo livre, mas rigoroso, e cabe à experimentação, guiada pela razão, testá-las. A razão deve ser livre, não se dobrando a interesses mesquinhos. Para o filósofo paraibano, o "racionalismo experimental" é o melhor método no exercício da razão em busca de uma compreensão profunda da natureza última da realidade.

\section{Liberdade e criação}

No pensamento de Pedro Américo, a liberdade cultural, conquistada pelos renascentistas, teria criado o ambiente intelectual aberto para os avanços revolucionários no campo da Filosofia Natural, como se a Arte tivesse nutrido, historicamente, a Ciência, fornecendo-lhe o alimento de sua gestação. A potência libertária do Renascimento e da Revolução Científica advém, segundo Pedro Américo, justamente de um exercício intransigente e arriscado da liberdade de pensamento. Os homens de espírito daquela época "ousaram pensar", mesmo sendo atacados por forças que teimavam em resistir:

Mas, em meio a todos esses conflitos, o que se perseguia, o que se queria ofuscar pelo terror era menos a adesão a uma hipótese astronômica qualquer do que a liberdade de exame científico. E o que Galileu, sobretudo, afirmou, defendendo Copérnico e se defendendo a si mesmo, foi, para a razão, o direito de ser emancipada, para a ciência, a faculdade de se desenvolver em toda a plenitude de sua independência (MELO, 1999, p. 58).

Para Pedro Américo, o que estava em disputa no caso de Bruno, Copérnico e posteriormente de Galileu, não era uma cosmologia, em sentido técnico, tampouco uma teoria astronômica, mas uma teoria da verdade e da ciência. Galileu não é condenado por defender o sistema copernicano, mas por defender que o sistema copernicano era mais do que um instrumento, um modelo de representação da natureza, sustentando que era verdadeiro. A dimensão filosófica da condenação é a defesa de Galileu de que a verdade é objeto da Filosofia Natural. A dimensão política é sua consequência direta. Se a Filosofia Natural pode se ocupar da natureza última da realidade, a Teologia perde o monopólio do real, o que desestabiliza a autoridade da Igreja.

A liberdade de pensamento é a condição de possibilidade da busca pela verdade. Por isso Galileu é um caso tão emblemático para Pedro Américo, pois encarnaria aquilo que no pensamento do filósofo brasileiro seria um princípio fundamental: a liberdade e a autonomia são alicerces não somente para a ciência, mas para toda vida civilizada. Nenhuma forma de viver poderia ser iluminada, rompendo com os limites estreitos da condição humana mais básica, sem usufruir de liberdade de pensamento e ação.

Essa indigna coalizão [autoridade suprema da fé, tradição, sentidos] aproveitou-se da mediocridade em que estavam mergulhados os sábios da época para sufocar o espírito de pesquisa e de livre exame perante o qual as doutrinas impostas começaram a aparecer como tantos atentados contra a consciência humana e a liberdade de pensamento (MELO, 1999, p. 51-52).

Recapitulemos o que avançamos, até onde caminhamos. Em linhas gerais, a concepção de ciência defendida por Pedro Américo é marcada pelos ideais de verdade, liberdade e racionalidade. O objetivo da ciência é a busca da verdade, isto é, do livre e desinteressado conhecimento 
da natureza, o que é reforçado pelo uso do termo "filosofia natural", que antes de ser apenas um modo corriqueiro de se referir às práticas de pesquisa da natureza, demarca uma posição não somente epistemológica como política. Os exemplos que Pedro Américo escolhe tomar como modelos de sua concepção parecem minuciosamente selecionados: os artistas do Renascimento e os filósofos naturais da Revolução Científica. Ao contrapor os renascentistas aos positivistas, ele reforça uma imagem de homem de ciências, artes e letras, que embora aceite "jogar o jogo" intricado das relações sociais, da busca por financiamento e por viabilização de seus projetos, não prescinde do cultivo dos ideais clássicos de verdade, bem e beleza.

Ao escolher seus modelos, ou aliados, dessa forma, ele oferece um contraponto de "peso" ao materialismo e positivismo crescentes, e se coloca, de certo modo, como herdeiro de uma tradição que não é "qualquer" tradição, mas aquela que nos legou as maiores conquistas tanto nas Belas Artes quanto nas ciências naturais. O veritismo de Pedro Américo, ou seja, sua ideia de que a razão de ser da ciência, o valor da ciência, é a busca da verdade, encontra seus alicerces na filosofia de Galileu, que é um dos personagens mais citados pelo filósofo brasileiro. Tomando Galileu como símbolo do filósofo que busca a verdade, ele ataca o positivista frontalmente. O positivista, como bem pontuou Farias Brito, teria renunciado à verdade e se afastado do absoluto, e em nome do que? De objetivos alcançáveis e concretos, como a utilidade, o progresso, o desenvolvimento. Parece que Pedro Américo quer pontuar que aquele que renuncia à verdade abdica da própria filosofia, como já Galileu expressara em Considerações sobre a opinião copernicana:

Quanto aos filósofos, se forem verdadeiros filósofos, isto é, amantes da verdade, não deverão irritar-se, mas reconhecendo que opinaram mal, deverão agradecer a quem lhes mostra a verdade; se a sua opinião permanecer de pé, terão causa de gloriar-se e não de irritar-se [Grifo nosso] (GALILEl, 2009, p. 124).

A filosofia não nos vacina do erro, não nos garante o acerto, mas tem o seu propósito, sua finalidade, na busca da verdade. Em nosso entendimento, o trecho acima demonstra um pouco da habilidade retórica de Galileu e do tipo de debate que Pedro Américo quer reproduzir. Assim como Galileu estava dialogando com os aristotélicos, filósofos e teólogos, Pedro Américo se dirigia aos positivistas e simpatizantes, lembrando-lhes que alguém só é verdadeiramente filósofo se for amante da verdade. ${ }^{11}$

\section{Considerações finais}

Para Pedro Américo a Revolução Científica e o Renascimento são movimentos de revitalização filosófica, conduzidos pela razão. Pensadores como Galileu realizam na Filosofia Natural as transformações profundas que Leonardo, Michelangelo e Rafaelo promoveram nas Belas Artes. A liberdade de criação e a autonomia de pesquisa, foram condições necessárias para tais florescimentos. Novamente, o Renascimento é tomado por Pedro Américo como modelo a

\footnotetext{
${ }^{11}$ Pedro Américo pretende lembrar o mesmo em relação aos positivistas. Poderíamos até objetar que tal comparação é sem cabimento, pois enquanto os positivistas possuem uma concepção claramente instrumental das ciências naturais, o mesmo não se aplica aos aristotélicos medievais. Contudo, veremos na próxima seção que Galileu foi condenado muito mais pela teoria da verdade que defendia do que pelo conteúdo físico de sua filosofia natural. Conforme Popper (1980), se tivesse ouvido Bellarmino, Galileu teria desistido de considerar que a filosofia da natureza é capaz de oferecer imagens verdadeiras do mundo, se restringindo a propósitos utilitários. Salvo as inúmeras diferenças entre o instrumentalismo tomista medieval e o positivismo moderno, em ambos os casos o que vemos são ataques à noção de que a ciência possa obter um conhecimento verdadeiro, ainda que incompleto e aproximado, do real, e uma defesa de seu valor instrumental.
} 
partir do qual os problemas filosóficos podem ser colocados. A relação entre ciência e arte seria íntima e profunda entre os renascentistas. A arte ofereceria à ciência o ímpeto criativo e a liberdade de ação, e a ciência ofereceria às artes os conhecimentos fundamentais para seu florescimento. Para o artista e filósofo da ciência brasileiro, os grandes nomes do Renascimento expressam uma personalidade ampla o suficiente para cultivar os vínculos entre Arte e Ciência, em uma concepção plural e ampla de cultura.

Pedro Américo está pensando o Renascimento para poder, a partir dele, tratar do ambiente intelectual do Brasil. A razão, quando livre, é revolucionária. Cria instrumentos, abre caminhos, reconfigura cenários políticos, abala sistemas de crenças, modifica a estrutura da realidade social, refaz os filamentos nervosos da tessitura histórica. Teremos, no Brasil, razão e liberdade? Gozaremos de uma razão livre?

Para Pedro Américo, nossa intelectualidade estaria refém do materialismo e do positivismo, assim como no medievo o mundo intelectual era refém da autoridade. Em Considerações filosóficas sobre as Belas Artes, Pedro Américo argumenta que o meio ambiente histórico-social é fundamental para o desenvolvimento do gênio humano. Ambientes inférteis, configurações empobrecidas, utilitárias, sentimentos hostis, impedem o florescimento de pessoas voltadas para as ciências, artes e letras (MELO, 2006, p. 196). "O gênio nada mais é do que um vigoroso talento, uma enérgica inteligência, fecundada pelo entusiasmo popular" (MELO, 2006, p. 195). Filósofos, cientistas e artistas não se produzem apenas por si próprios, eles precisam, em grande medida, das condições sociais propícias para se formar. Devem encontrar na sociedade o fermento intelectual adequado, e a estufa cultural necessária. Conforme Pedro Américo, "o instinto das massas e as aspirações da época determinam tanto a marcha do gênio, como a pressão de sua própria natureza" (MELO, 2006, p. 195).

Assim como as Belas Artes buscam a beleza e a harmonia, as ciências almejam a verdade. Ciência e Arte formam, no pensamento de Pedro Américo, um sistema em que uma completa e inspira a outra. Junto às letras e ofícios, provêm o caudal que deve alimentar a cultura. Mas não carecemos de indivíduos artísticos ou de cientistas, mas de sociedades capazes de criar as condições propícias ao desenvolvimento de suas obras. Para Pedro Américo, a cultura não é obra de gênios isolados, mas de arranjos sociais, coletivos. "O homem nada produz se a ação coletiva dos outros homens. É a cooperação da sociedade, que lhe infiltra nas veias o calor necessário para as grandes criações" (MELO, 2006, p. 197).

Suas considerações sobre a natureza coletiva, social e histórica das ciências, artes e letras, indicam a crítica sutil que faz da sociedade brasileira de sua época: Se o Brasil quer cientistas, artistas e literatos, deve produzi-los. A crítica deve ser sutil, pois Pedro Américo depende da rede de mecenato do monarca. Ao chamar a atenção para a sociedade e o espírito da época, parece indicar, no entanto, que o mecenato, por mais amplo e "generoso" que seja, não basta. A própria sociedade deve amadurecer, tornar-se o solo fértil para que gênio de sua gente disponha dos nutrientes sociais e históricos necessários para germinar.

E quais são as condições necessárias para o cultivo do engenho de um povo, a adubação de um solo comum onde o Espírito possa florescer? Já as enumeramos e trabalhamos ao longo do texto. A receita de Pedro Américo combina a busca da verdade com o exercício da liberdade de pensamento e criação, o racionalismo experimental e a curiosidade intelectual com o desinteresse (interesse interno). Tais elementos são necessários, mas não suficientes. Para obtermos algum resultado, eles devem ser incorporados à vida social, tornar-se filamentos da tessitura social e notas características do momento histórico.

Em Pedro Américo notamos claramente que toda concepção de ciência, por mais esotérica e heurística que seja, é também um projeto político e uma reflexão existencial, pois sempre 
que elaboramos uma resposta para a questão "ciência para quê?", somos obrigados a responder também ao "como" e ao "para quem", ou, dizendo de outro modo, a forma como respondemos a questão do valor da ciência, ou que tipo de ciência queremos, com quais valores, movida por quais ideais, responde igualmente outras questões mais amplas, como o tipo de vida cultural, e portanto, de sociedade que desejamos, o ideal de processo civilizatório que cultivamos. Quando pensamos a ciência não somente como um conjunto frio de práticas e resultados, mas como cultura, como forma de vida, o modo como respondemos o que é a ciência diz mais sobre nós mesmos - diz o tipo de resposta que desejamos dar para aquelas questões fundamentais, espantosas e sempre atuais: Quem somos nós? Que tipo de vida vale a pena vivermos? Em Pedro Américo não somente levantam-se tais questões. Ensaiam-se respostas.

\section{Referências}

A COMÉDIA SOCIAL. O que vai por ahi. A Comédia Social: Hebdomadario Popular Satírico. Anno I, n. 9, 1870. p. 3.

BARROS, Francisca Argentina Gois. A arte como princípio educativo: uma nova leitura biográfica de Pedro Américo de Figueiredo e Melo. 2006. 186f. Tese (Doutorado em Educação). Universidade Federal do Ceará, Faculdade de Educação, Programa de Pós-graduação em Educação Brasileira, Fortaleza, 2006.

BOLTZMANN, L. Escritos Populares. Trad. Antonio Augusto Passos Videira. São Leopoldo: Unisinos, 2004.

COHEN, B. Hypotheses in Newton's Philosophy. Boston Studies in the Philosophy of Science, 5 (1969). p. 304-326.

COHEN, B. The first english version of Newton's Hypotheses non fingo". Isis 53/3, (1962). p. 379-388.

EINSTEIN, A. Eine neue Bestimmung der Moleküldimensionen. Annalen der Physik, Band 19, 1906, In Ann. Phys. (Leipzig) 14, Supplement (2005). p. 229-247.

EINSTEIN, A. Física e realidade. Rev. Bras. Ensino Fís. 28, n. 1.

FARIAS BRITO, R. Finalidade do Mundo. Vol. 1. Brasília: Edições do Senado Federal, 2012.

GLICK, Th. O positivismo brasileiro na sombra do darwinismo: o grupo ideia nova em desterro. In: DOMINGUES, HMB.; SÁ, MR.; GLICK, T. (Orgs.). A recepção do Darwinismo no Brasil [online]. Rio de Janeiro: Editora FIOCRUZ, 2003.

KOYRÉ, A. Do espaço fechado ao universo infinito. Rio de Janeiro: Forense Universitária, 2006.

KURY, L. Homens de ciência no Brasil: impérios coloniais e circulação de informações (17801810). Hist. cienc. Saúde - Manguinhos, 11/1 (2004). p. 109- 129.

MACIAL, F. O jovem Pedro Américo, entre Arte, ciência do Belo e um outro nacional. São Paulo. Tese (Doutorado em Artes) Universidade de São Paulo, 602f., 2016.

MELO, Pedro Américo de Figueiredo. A ciência e seus sistemas: Questões de História e Filosofia Natural. Trad. G. Oliveira. João Pessoa: Editora Universitária UFPB, 1999.

MELO, Pedro Américo de Figueiredo. A ciência e seus sistemas: Questões de História e Filosofia Natural. 4. ed. Trad. G. Oliveira e M. Coutinho. João Pessoa: Editora Universitária UFPB, 2001. 
MELO, Pedro Américo de Figueiredo. Considerações filosóficas sobre as Belas Artes entre os antigos. João Pessoa: Editora Universitária UFPB, 2006.

MIGUEL, L. R. Wiliam Whewell: as motivações e os objetivos de um filósofo da ciência. In:VIDEIRA, A. (Org.). Perspectivas contemporâneas em Filosofia da Ciência. Rio de Janeiro: Eduerj, 2012.

NEWTON, I. The Principia Mathematical Principles of Natural Philosophy. Translation I. Bernard Cohen and Anne Whitman. Berkeley: University California Press, 1999.

OLIVEIRA, J. M. Pedro Américo. Sua vida e suas obras. Rio de Janeiro: Imprensa Nacional. Ministério da Educação e Saúde, 1943.

POPPER, K. Três concepções acerca do conhecimento humano. Trad. P. Mariconda e P. Almeida. São Paulo: Abril Cultural, 1980. (Coleção Os Pensadores).

ROMERO, S. A philosophie no Brazil. Porto Alegre: Tipografia de Deutsche Zeitung, 1878.

SILVA, V. Teoria quântica, Física Nuclear e Filosofia Grega. Griot, v. 15, n. 1, 2017. p. 233-250.

SILVA, V. Um ideal de ciência: José Leite Lopes e a História da Física no Brasil. Ciência e Sociedade, v. 6, n. 2, 2019. p. 35-47.

VIDEIRA, A. (Org.). Henrique Morize. Rio de Janeiro: Fundação Miguel de Cervantes, 2012.

VIDEIRA, A. A inevitabilidade da Filosofia na Ciência Natural do século 19: O caso da física teórica. ljuí: Ed. da Unijuí, 2013.

VIDEIRA, A. As descobertas astronômicas de Galileu. Rio de Janeiro: Vieira e Lent, 2009.

VIDEIRA, A. Filosofia da Ciência sob o signo dos Science Studies. Abstracta, v. 2, n. 1, 2005. p. 70-83.

\section{Sobre o autor}

Vinícius Carvalho da Silva

Professor da Universidade Federal do Mato Grosso do Sul (UFMS). Doutor em Filosofia da Ciência e Teoria do Conhecimento pela Universidade do Estado do Rio de Janeiro (UERJ).

Recebido em: 21/07/2020.

Aprovado em: 21/09/2020.
Received: 21/07/2020.

Approved: 21/09/2020. 